\title{
Globalisation, internationalisation, and language education: an academic program for global citizens
}

Roby Marlina

Correspondence: Roby.Marlina@monash.edu Monash University, Melbourne, Australia

\section{Introduction}

The inextricably interconnected world created by the rapid forces of globalisation has prompted many educational institutions at all levels of study and within a wide range of disciplines to re-conceptualise the kind of knowledge, mindsets, and skills they expect their students to develop. Many tertiary institutions, in particular, have started to develop and/or have developed strategic plans to internationalise their education. They offer - or claim to offer - learning programs/curricula that provide their students with international exposure and equip them with intercultural knowledge, intercultural mindsets, and intercultural communication skills. In practice, as providers of 'internationalised education', some universities establish a policy of compulsory English

(c) 2013 Marlina; licensee Springer. This is an Open Access article distributed under the terms of the Creative Commons Attribution License (http://creativecommons.org/licenses/by/2.0), which permits unrestricted use, distribution, and reproduction in any medium, provided the original work is properly cited. 
language instruction for all students from all disciplines. This is probably driven by the awareness of the international status and increasingly significant functions of English in today's world. Other universities emphasise the incorporation of issues related to cultural diversity, multiculturalism, or intercultural communication into all learning programs. However, there has often been a mismatch between the rhetoric and reality. In other words, though the institutions claim that their programs/curricula are internationallyoriented, in practice, they still have not been able to escape a monocultural-chauvinistic perspective. Therefore, Trevaskes, Eisenchelas, and Liddicoat (2003) question whether learning programs exist that truly provide 'internationally-flavoured' education which genuinely prepares its graduates for the landscape globalisation has created.

In this paper, I shall present a case study of how an international/intercultural-communication-focussed undergraduate program offered by a university in Australia has attempted to respond to this landscape without falling into the trap of an Anglo-centric mindset. On the basis of in-depth interviews from four former students of the program, I shall disclose the contributory role(s) they believe this program has played in prompting them to develop the knowledge and worldview/perceptions for living effectively in today's international and intercultural globalising environments. Prior to this, I shall discuss the conceptual frameworks upon which the premises of this paper's arguments are based.

\section{Theoretical frameworks}

\section{Globalisation: its various interpretations}

The concept of 'globalisation' is not an unfamiliar concept as it has been widely and 'hotly' discussed by scholars from a wide range of academic disciplines including history, political science, cultural studies, education, economics, and sociology. The meaning of this concept has become rather 'elastic', leading the cultural critic Jameson (1998) to remark that globalisation has become "the modern or postmodern version of the proverbial elephant, described by its blind observers in so many diverse ways" (p. xi). In his critical analysis of the definitions of globalisation found in most academic, corporate, official and popular discussions of things global Scholte (2002), isolated four concepts/terms that are often regarded as equivalent to the concept of globalisation: internationalisation, liberalisation, universalisation, and westernisation (refer to Scholte's paper for the definition of each term). However, since these do not provide "important insights into historically relatively new key circumstances of our time" (Scholte 2002, p.13), he proposes instead to view globalisation as "the spread of transplanetary connections between people" (ibid, p. 13). In other words, globalisation involves unprecedented growth in transworld contacts, meaning that the porosity of geographical borders increasingly allow global citizens to "physically, legally, culturally, and psychologically engage with each other" (ibid, p.14). Specifically, the rise and expansion of transnational corporations, increased human mobility across the globe, and the advancement of information communication technology has increased the frequency of encounters between people from different parts of the world. Physical or virtual access to people from other backgrounds can result in exchanges of trades ideologies, worldviews, values, and cultural practices. As such a view of globalisation emphasises the significant roles of mass communication, observed by McKay and Bokhorst-Heng (2008), it will be used as a conceptual framework in this paper. 


\section{Internationalisation of education}

Responding to the above 'landscape' that globalisation has created, many educational institutions, particularly universities have a policy and have developed strategies of internationalisation (Haigh 2002; Yang 2002) in which graduates are required to learn to develop important knowledge, awareness, and skills to communicate across cultures. As the concept of internationalisation of education is diversely conceived, different universities have their own understanding of the concept and, therefore, their own practices of internationalising its education. Observing how different universities implement their understanding of this concept, Trevaskes et al. (2003) divide internationalisation into weak and strong forms. Driven by a 'marketing and quality assurance paradigm', the weak form of internationalisation shows concern for maximising profit through the recruitment of fee-paying international students. Trevaskes et al. (2003) argue this is a superficial engagement with internationalisation. In line with Knight and de Wit's (1997) view of internationalisation as a meaningless term unless there is a conscious effort to integrate intercultural dimension into education, the strong form emphasises developing internationally/interculturally-focussed learning programs and curricula. In these issues of cultural diversification and the aim to equip students with the knowledge and skill base to engage successfully in intercultural communications and relations is central.

Even though universities claim to have adopted the strong form of internationalisation, it has been shown that this claim is still far from being realised (Briguglio 2007; Hayward 2000; Stier 2004; Stella \& Liston 2008; Trevaskes et al. 2003). The question of whether programs/curricula that truly reflect the strong form of internationalisation exist has been raised. A world-wide survey of internationalisation by the International Association of Universities in 2003 found that "while two thirds of the institutions appear to have an internationalisation policy/strategy in place, only about half of these institutions have budgets and a monitoring framework to support the implementation" (Knight 2003, p.4). Australian universities, in particular, while claiming to have developed an internationalised curriculum as a means to inculcate cultural diversity, demonstrate no measures of success (Stella \& Liston 2008). In other words, the strong form of internationalisation seems to remain only at a theoretical level, while at practical level, universities cannot escape the weak form and a monocultural chauvinistic approach to internationalisation. A typical example of this is universities' acknowledgment (often with pride) of the presence of large numbers of international students on local campuses, in the belief this is helpful for all students to gain international understanding. This is evidenced in a report on the nature of international education in Australian universities, which claims that "by seeing people from other backgrounds around on campus and in classes, Australian university students will gain international perspective and cultural understanding" (Universities Australia 2009, p.40). There seems to be minimal attempt made to educationally utilise this cultural and linguistic richness to develop a "culturally literate, interculturally capable society in Australia" (Trevaskes et al. 2003, p.10). Even if there is, the attempt seems to go as far as including international perspectives in a learning syllabus and maybe adding word 'international' to a title of a course(s).

Another strategy of internationalisation of education that has been implemented by some universities in the world is the teaching of English Language. In countries where 
English is the national and/or official language, some universities incorporate "isolated remedial [English language] classes within the normal degree structure" (Haigh 2002, p.57) for 'non-English' speaking background international students so that they are "up to speed with the dominant tradition" (ibid, p.57). In countries where English is not the national and/or official language, some universities mandate the teaching of English to students from all disciplines and adopt English as the medium of instructions (Carrol-Boegh 2005; Manakul 2007). However, these practices are still problematic and have been criticised for not 'internationalised' enough for a number of reasons. Firstly, the isolated remedial language classes create a binary opposition of usand-them and a view of 'non-English' speaking background international students as deficits. They also legitimise the view of the mainstream tradition as unquestionably normal, and restrict the incorporation of multicultural skills into the system at large (Haigh 2002). Secondly, internationalisation will remain monolingual and monocultural and supportive of the parochialism in scholarship if English is the only language that students are required to learn and use to gain knowledge. As Liddicoat (2003) argues:

"Internationalisation...through the teaching of English and teaching in English to international students...lacks the dimension of diversity... and therefore does not adequately reflect the rhetoric of plurality and interculturality which accompanies proposals for internationalisation". (p.23)

Sharing a similar view, Marginson (1999) argues that teaching English as a strategy of internationalisation is "a form of soft imperialism which imposes 'Western' ways of thinking, doing, and acting" (p.19). Therefore, an internationalised education needs to break out of an English-only mindset by mandating the learning of languages other than English. It is indeed undoubtedly true that learning languages other than English can guide students to develop international and intercultural communicative competence.

However, teaching and learning English also does not necessarily mean that (1) students are 'Westernised'; (2) monolingualism and monoculturalism are promoted; (3) and education fails to reflect the rhetoric of plurality and interculturality. The question is to what extent have the educators taken into account the changing sociolinguistic landscape of English in teaching the language?

\section{English as an international language (EIL)}

The above criticism of English language teaching as a means of internationalisation of education is based on a view of English as a unitary concept and the language of the 'West'; and thus has overlooked the current sociolinguistic reality of English. The global expansion of English, leading to the pluralisation of its users and forms, and the significant role of English in various international cultural and economic arenas have given English the status of an international language. Hence, the view of English as a homogeneous language of the 'West' is anachronistic for a number of reasons.

Firstly, one of the main factors that contributes to the status of English as an international language is the changing demographic background of its users. It has been widely agreed that the predominant users of English in the world today are bilingual and multilingual speakers of English from, what Kachru (1986) termed, 'Outer Circle' Countries - such as Singapore and Nigeria where English is used as an institutionalised 
language in conjunction with other official languages) - (hereafter OCC) and 'Expanding Circle' countries - such as South Korea and China where English is learned and taught as a foreign language - (hereafter ECC). Statistically, there are approximately 1 billion reasonably competent speakers of English from those circles (Jenkins 2009) who acquire English within their bi- and multilingual repertoires, use English and perhaps other languages in multilingual contexts, and use English to communicate predominantly with other bi-/multilingual speakers of English (Crystal 1997; Graddol 2006). Although it is difficult to determine the exact numbers of these speakers of English, it is clear that the numbers of individuals from these circles are growing and have exceeded the numbers of speakers from Inner Circle countries (hereafter ICC) where English is spoken as the national language (Bloch \& Starks 1999; Graddol 1999; Jenkins 2009; McKay 2003).

Secondly, the global expansion of English and the increase in the numbers of bi/multilingual speakers of English in the world have also led to emergence of different varieties of world Englishes (Graddol 2001; Kachru 1986) and have defined English as a pluricentric language with multiple grammars, vocabulary, accent, and pragmatic discourse conventions. When English enters a particular society, the language and its culture are not passively absorbed and internalised by members of that society. Rather they are 'nativised' (Kachru 1986), 'appropriated' (Canagarajah 1999), and 're-nationalised' (McKay 2002) to "suit the local tastebuds" (Marlina 2010) and to project their own cultural and linguistic identities. Therefore, with its pluralised forms, English is a vehicle for users of English to project their cultural identities and to express their cultural conceptualisations (Sharifian 2011) to those outside their local milieu. Users of English from OCCs and ECCs may not necessarily communicate in Inner-Circle varieties of English and therefore the worldviews, pragmatic norms, and cultural values of those countries. Rather, as bi-/multilingual speakers of English, these users of English are likely to speak their varieties of English in which their cultural values, pragmatic norms, and worldviews are embedded. As Smith (1976) describes, they are likely to display their emotions such as anger, joy, affection, surprise, hate etc., in the same way as they always have, but in English. With their bi-/multilingual repertoire, communication between these speakers is not likely to take place only in English, but also in other languages or in a code switching manner between English and other languages.

This rapid development of English has encouraged Applied Linguists and TESOL scholars to shift its notions of English education from the traditional ESL ('Inner-CircleEnglish-oriented') paradigm to the EIL (English as an International Language) paradigm (Matsuda 2012a; Sharifian, 2009) which emphasises the importance of teaching English as a pluricentric language for international/intercultural communication. Recent publications (Alsagoff, McKay, Hu \& Renandya, 2012; Matsuda 2012a) provide English language educators with ways in which this paradigm can be incorporated into their curriculum and pedagogy. Thus, drawing from a number of researchers and scholars (Marlina \& Ahn 2011; Marlina \& Giri 2009; Matsuda 2002, 2005, 2012b; McKay 2012) who are proponents of the paradigm, the following are proposed key principles that need to inform the teaching and learning of English in today's era of globalisation:

- The variety of English needs to be relevant to the local learning contexts.

- Examples of different varieties of world Englishes should be present. 
- The cultures and users of English from Outer and Expanding Circle countries should be more prominently represented.

- Interactions in English between bi-/multilingual speakers of English should be present.

- The discourses of cultures and users of English from Outer and Expanding Circle countries should be presented in a non-ethnocentric manner.

- Multilingualism should be promoted by recognising and including languages other than English spoken by the students.

The first principle may need to be re-visited in the light of the landscape that globalisation has created. Although it is important for students to learn a locally relevant variety of English, globalisation has blurred which variety(ies) of English is/are and will be locally relevant. Mass migration and advancement of communication technology have led world Englishes to travel from one circle to another (Clyne \& Sharifian 2008). Thus, the linguistic and cultural backgrounds of potential interlocutors with whom learners will interact in English are often unknown as is the variety of English that will be used. Since global citizens cannot avoid "bathing in the sea of linguistic variety" (Crystal 1999, p.19) and encountering variation in cultural and linguistic behaviour, the variety (ies) of English to which learners need to be exposed should be glocally relevant.

\section{Responding to globalisation and internationalisation: the undergraduate EIL program}

Using the above theoretical discussions as frameworks, this section presents a case study of how an international/intercultural-communication-focussed undergraduate program, i.e. English as an International Language (EIL) program offered by an internationally-oriented Australian university (UniR - pseudonym) has responded to globalisation and attempted to accomplish the university's mission of the internationalisation of education. Specifically, it showcases how students are guided at both the program and classroom level to professionally develop the knowledge and skills base important for living in today's era of globalisation.

\section{Program level}

To respond to globalisation and the university's mission of internationalisation, the initial undergraduate EIL program (formerly known as EIU - English in Use) that taught the use of English in the Australian academic discourse community to 'non English' speaking background (NESB) international students was revised. The main reason was to reform a deficit, monocultural-chauvinistic, and assimilationistic approach to language education that underpinned the EIU program. This was reflected in the isolationist' nature (Haigh 2002) of the program in which only NESB international students were able to study EIU and how they were continuously required (throughout their study in the program) to identify and learn to overcome 'problems' they, as bi-/multilingual speakers of English, faced in operating 'successfully' within Australian society and the academic discourse community.

By contrast, this newly revised undergraduate EIL program is an academic contentdriven program that adopts the EIL paradigm (McKay 2002; Sharifian 2009) to teach 
international/intercultural communication to students from all backgrounds. It provides them with knowledge of English language variation and its implications for communication in English, teaching and learning English, as well as researching English in a variety of intra/international contexts. As cultural and linguistic diversity is the core of the program's curriculum, its main general objectives are to:

- guide students towards developing knowledge of English language variation,

- foster the mindsets, attitudes, and skills to communicate effectively with speakers of Englishes from diverse lingua-cultural backgrounds in a variety of intra/ international contexts, and

- (for future English teachers) develop understanding of the complexity of today's English language pedagogy, and the skills to teach EIL.

To achieve these objectives, eight subjects are developed for EIL students at different levels of study. Two of the subjects studied by freshmen provide an introductory exploration of the notion of language variation (in what ways language varies and why) and, based on Kachru and Smith's (2008) notion of 'Interaction as Cooperation', an investigation of what communicative strategies that international communicators need to learn to develop in communicating across those language varieties. Two further subjects studied by sophomores take these ideas one step further by exploring the impact of globalisation on the use of English in face-to-face and online communication; and the use of English in media and popular culture. Sophomores are introduced to research practices and are required to conduct a small-scale project on any EIL topic of their choice. The last four subjects provide senior year students with opportunities to explore in greater depth and to do further research on the diversity of English and its implications in specific areas. The subjects range from the study of World Englishes (all aspects of English in ICC, OCC, and ECC) to the study of language and culture; and from writing in EIL to the pedagogy of EIL.

As an internationally-oriented program, the program welcomes students from diverse lingua-cultural backgrounds regardless of the Kachruvian circles from which they originally came. Therefore, having students from up to twelve different nationalities in one class is not rare. EIL students not only come from the disciplines of Languages and Humanities/Social Sciences, but there have also been a large number of students from Business and Economics, Information Technology, Education, Sciences, and Engineering taking EIL as part of their university degree.

\section{Classroom level}

Asserting the internationally-oriented objectives and subjects of the program is insufficient to justify the fact that the EIL program is an internationalised program that prepares its graduates to operate flexibly and successfully across cultures. What happens inside the classrooms needs to be discussed because the 'exterior' of any program sometimes does not mirror its 'interior'. Therefore, this section showcases what the EIL lecturers teach in the classroom in order to help the program accomplish internationalisation and also to guide their students towards developing the knowledge, mindsets, and skills necessary for living in today's era of globalisation. 


\section{Which language?}

As this program teaches students about intercultural communication and the use of English for international communication, the language focussed upon is of course on English, but English with an emphasis on its plurality. In almost every lesson, the EIL lecturers incorporate examples of different varieties of world Englishes from various circles either as the main topic for a lesson (e.g. English in Singapore) or when presenting examples to illustrate particular linguistic concepts (e.g. basilect vs acrolect). Students are encouraged to, not just be aware of these differences, but also to study, analyse, and interpret these different varieties. As classroom learning activities, students are given communicative scenarios in which they encounter a variety(ies) of English with which they are not familiar, and learn to develop the attitudes and strategies for dealing with unfamiliar communicative encounters.

As multilingualism is a characteristic of today's international exchanges, the EIL lecturers are fully aware that it is impossible to teach EIL without incorporating other languages. Given the multilingual repertoires of the students, the lecturers often solicit examples from their students' other languages and invite them to explain those examples to their classmates (and the lecturers). For example, a lesson on politeness across cultures often includes in-depth discussions of honorifics from different languages and how they are being used by bilingual/multilingual speakers of English in their communication in English. Not only do the lecturers aim to promote multilingualism as the reality of today's communicative exchanges, but also to show that knowledge of other languages is important for ensuring the success in international exchanges.

\section{Which and whose cultures?}

As English has become a vehicle for users of English to communicate their worldviews and cultural values, lecturers of the program often use examples from different varieties of English (especially OCC and ECC Englishes) to teach and illuminate cultural practices, values, worldviews, and beliefs of the Outer and Expanding Circle countries. (Of course this is done with full awareness of the risks of generating and perpetuating stereotypes). This does not mean that the varieties of English and cultures from ICC are neglected. They are also included in the curriculum and discussed in classrooms. Though there are some students who demand ICC Englishes and cultures to dominate the curriculum of the program, the educators respond by referring to the multiculturality of Australia (and other ICCs) as well as to the variation of linguistic and cultural behaviour as the characteristic of communicative encounters in today's globalisation era.

A pedagogical strategy often used by the EIL lecturers to promote intercultural learning is using students' cultural knowledge, local stories, cultural practices, and worldviews as invaluable learning resources. The classroom learning activities are designed to diminish the role of lecturers as the knowledge-providers by prompting students to use their 'cultural' and 'linguistic' capital (Bourdieu 1991) to educate their lecturers as well as classmates about their cultures. For example, in a lesson on politeness in writing across cultures, students are given a scenario in which they are asked to write a professional letter responding to a customer's complaint. Monolingual English speakers respond in English, whereas bi-/multilinguals write initially in their own mother tongue and then translate their letter into English. When students are required to share their analyses of the macro- and micro-structure of their letters and explain the reasons 
behind those structures, they also share their own cultural values, worldviews, and pragmatic norms; and how these are embedded within their letters. Not only does this exercise allow everyone to gain an intercultural understanding, but it also provides students with opportunities to learn how to communicate their cultures in English to those who are unfamiliar with them.

\section{What issues are being addressed?}

To guide students towards becoming intercultural communicators, knowledge of the English language and cultural differences is not sufficient. For this reason, the lecturers often refer to the issue of the politicisation of cultural and linguistic differences. Specifically, the lecturers raise students' awareness of existing ideologies, practices, and policies in any societies that unjustly empower some people and marginalise others based on their racial background and the language and/or the variety of English they speak. In addition to using their own personal observations and experiences, lecturers use movies, newspaper articles, policy documents, teaching materials, and even Youtube clips to bring the above issues into the classroom. Concepts/issues such as the unproblematised dichotomy of 'native' and 'non-native' English speakers, native-speakerism (Holliday 2005); Standard Language ideology (Lippi-Green 1997), linguicism (Skutnabb-Kangas \& Phillipson 1989), linguistic imperialism (Phillipson 1992), boutique multiculturalism (Kumaravadivelu 2008), and creative destruction (Rubdy 2001) are discussed.

Using these concepts as their analytical lenses, students are encouraged to critically reflect on their experiences and observations of using/teaching/learning English. They are urged to unpack any 'hidden politics' lying behind their experiences and observations of (the discourses of) the use of English as well as the pedagogy of English in a variety of intra/international contexts. More importantly, students are encouraged to investigate and propose strategies that can be employed to challenge this linguistically based social injustice. As these issues are sensitive, many students resist discussing them openly in classrooms due to fear of offending their classmates. In response to this, the lecturers have developed an online discussion forum where students can courageously present a critical viewpoint on these issues while remaining anonymous.

\section{How are students assessed?}

The EIL lecturers have developed a wide range of assessment tasks to guide students towards developing their knowledge of EIL and intercultural communication as well as the ability to communicate across cultures and Englishes:

- Journal Entry - this task requires students to write in diary form their observations of and critical reflections on the theoretical concepts or debates/issues in their daily life. For example, students are asked to collect examples of different varieties of world Englishes they encounter in their daily life.

- Reflective Oral Presentations - the focus of this task is similar to the journal entry, but the students are asked to deliver their discoveries in a form of an oral presentation. Students are also required to develop activities to engage their classmates in reflections or critical dialogues.

- Position Paper - this task requires students to use the form of an academic essay to write about their stance, including a critical response, in relation to a particular 
issue. Their response/stance will need them to engage with the theoretical issues as well as to reflect critically on their experiences in using/learning/teaching English and (if applicable) other languages.

- Critical Movie Analysis - as the name of the task suggests, students are asked to use the theoretical concepts/issues they have encountered as conceptual 'tools' to analyse movies such as The Other End of The Line, The Namesake, Kite Runner, Outsourced etc. which contain intercultural stories/issues and examples of the use of different varieties of world Englishes.

- Research Report - this task requires students to conduct a small-scale research project on any EIL-related topic. It involves data collection for which the students are required to carry out survey and interviews.

- Simulation/Case Study Project - this is a problem-solving project in which students (who are assigned the role of an EIL adviser) are required to work in groups and solve a case or a scenario which consists of issues and problems that arise from cultural and linguistic differences. Not only do students write their responses, but they also have to present them orally either in a form of a role-play or a panel presentation.

- Classroom-research Project - this project requires students to report on their critical analyses of a number of English language learning classrooms they are required to observe from the perspective of EIL. Their report must include their critical observations and analysis of the English teachers' teaching methodology, learning materials, classroom activities, the linguistic/cultural focus, and classroom interactions.

Although each assessment task has its own focus, they all assess students on the following skills: reflections, problem-solving, analytical, critical-thinking, application (the ability to link theory into practice), and communication (this includes their ability to employ communicative strategies to share their cultural values, practices, and worldviews in English). The tasks also assess students on their knowledge of the current sociolinguistic reality of English, their awareness of the impact of globalisation on using/learning/teaching English, and the effectiveness of the communicative strategies they propose to employ (in written tasks) or demonstrate (in oral tasks) in dealing with unfamiliar intercultural exchanges and/or linguistic and issues of social inequality.

\section{The efficacy of the EIL curricula: from students' perspectives}

However much the lecturers believe the program and curricula have successfully provided an internationalised education that graduates students well prepared for living in today's globalised world, the extent to which this confidence is warranted lies in the outcomes for the students. Thus, this section presents analyses of the learning experiences of four former EIL students - Cheolsoo (South Korea), Tomoko (Japan), Phil (Australia), and Ogilvy (Australia; all names are pseudonyms) - who volunteered to be interviewed for the author's doctoral project. It specifically addresses the students' attitudes/views towards English language variation prior to studying in the program and their experiences of how they were prompted to critically (re)examine those attitudes/ 
views. At the time of the interviews, Cheolsoo and Ogilvy had completed two freshmen level EIL subjects whereas Tomoko and Phil had completed a major in EIL.

\section{Difference $=$ deficiency}

As expected, all participants entered the program with minimal understanding and awareness of English language variation; and therefore with a belief in the supremacy of speakers of English from ICCs, and a deficit view of speakers of Englishes from OCCs and ECCs. Thus all participants seemed to be aware of 'differences' (being and sounding different), but these differences were regarded as deficiencies that needed to be remedied.

Both Cheolsoo and Tomoko enrolled in the program with a similar intention, which was consistent with the aim of the program, i.e. to "learn how to use English internationally". However, when prompted to further explain what they meant by this intention they both seemed to reveal a self-deprecating and deficit view of their English. Cheolsoo and Tomoko reported that they expected the program to 'remedy' their use of English and their Korean/Japanese accent and to "help" them speak like Australians or other English speakers from ICCs so that they would not feel "behind". In other words, learning how to use English 'internationally' seemed to be viewed as learning how to speak like an Australian or American.

expect to learn how to talk like Australians or maybe Americans and improve my English because I have a Korean accent (Cheolsoo)

Since I came to Australia, I always felt that I am a bit lower grade, my self-esteem was damaged because I was told that I couldn't speak English like the local people and I had some 'accent'. If I can't speak English like Australians, I'd be behind them. So, I expect that the program correct our English and help us improve it (Tomoko)

As they shared their reason for wanting to sound like Australians or Americans they further showed their belief in the supremacy of those speakers and the exclusive effectiveness of their forms of English for international communication:

When you speak English like Americans, it sounds better and can help you talk with anyone in the world, but not with other Asian or Korean accent (Cheolsoo)

When I came to Australia, I see a lot of multicultural people and I feel I had a label, white people, American, British are superior, are the only English speakers in the world and a good communicator in English, and then maybe Asians (laughter) and the rest of them are you know....(laughter). If people have their accent or if they are not really fluent in speaking native-English or in communication, I would just like ok ok please don't speak (Tomoko)

Ogilvy initially entered a program with an intention to learn about how to "communicate across cultures", which was consistent with the program's aim. Analysis of further conversations seemed to reveal the deficit and native-speakerist perspective underlying his intention. Speakers of English from OCCs and ECCs were viewed as 'learners' and their distinctive use of English was perceived as "difficulties, foibles, and speed-bumps". 
seeing how international people study English and be able to maybe understand sort of foibles, the speed-bumps, the way they study the language, the difficulties they have in approaching English (Ogilvy)

When asked to further explain what he meant by 'international people', 'difficulties', and 'foibles', he referred to his classmates who were "Singaporeans and Malaysians who have much weaker grasp of English than [himself], were not familiar with Australian English, use phraseology incorrectly or expression incorrectly, and speak with staccato tone". Therefore, learning how to communicate across cultures seemed to be viewed as learning to understand and perhaps sympathise with the "difficulties", "foibles", and "speed-bumps" that speakers of English from OCCs and ECCs faced.

Phil, on the other hand, had a completely different intention from the other participants. His impression of his first EIL lesson revealed an even stronger deficit and native-speakerist view of speakers of English from OCCs and ECCs than the other participants:

the room is full of fobs and these guys can't even speak English...And when my other Australian friends found out, they're like, 'English as an International Language? Phil, what the hell are you doing in the unit which is for the fobs?'...A lot of my friends think that it is actually a joke. And Im like, 'yeah, Im kicking arse'. So, in the class, since I am very confident in my English ability, I took over the classroom and discussions (Phil)

When he was asked to further explain what he meant by 'can't even speak English', he referred to his experiences of interacting with speakers in his classrooms and at his workplace:

I remember when I spoke to these fobs during classrooms discussions and they have weird accent, you can't understand them, and then give up. So, all Asians who walk into my bottle shop don't speak English...I used to see that...Chinese walk into the shop, I was like 'oh my god, he only speaks Chinese, I can't be bothered with him, I completely leave him alone (Phil)

In response these 'differences', all four participants believed that speakers of English from OCCs and ECCs needed to be 'assimilated' and taught to speak 'Standard Native English' in order for effective international communication to happen:

these people need to learn Global Standard English because it is incorrect and inaccurate form of English. Definitely not understandable to native-speakers. Im sure using formal speech or called Global Standard English would be the way to combat this (Ogilvy)

that whole assimilation into the society, that whole do the way Romans do thing, that fobs who don't speak English and speak English with weird accent need to lose your accent, become part of us and speak Standard native English (Phil) 
Native English needs to be taught cos they are standard. If you want to communicate in English better with anyone and people from everywhere, I think it is more effective. So, learning how to speak like Americans is kinda like the good way (Cheolsoo)

I mean, I don't care if you sound differently, if you speak like non-native English, you have to be corrected and changed into speaking native Australian English so that you can communicate better with other people right? (Tomoko).

\section{The instructional effects: "Definitely learnt a useful lesson already"}

Reflecting on their experiences of studying in the program and interacting with the lecturers and other students in the class, all participants asserted that the EIL curricula had somewhat prompted them to develop knowledge, attitudes, and skills they needed for using English to communicate across cultures. The differences in the way English is used as a result of its global spread was one major element of the curricula which all of the participants believed had "broadened our horizons of the language" (Ogilvy). Knowledge of world Englishes was regarded as important and relevant to (for some) their daily life and (for others) their future.

Different varieties of English is very impressive to me. I was also so impressed to see Korean English. I was like Wow! I have never thought about English in that way... Now I want to recommend people to go to different countries like Korea and listen to the way people speak English to broaden their perspectives of English spoken in the world...It is important to learn about the diversity of English especially in today's globalisation...It's so true that I have lecturers who do not necessarily speak Australian English, but they are from China, India, Sri Lanka, and Italy who speak their variety of English (Cheolsoo)

I used to think that American, British or the Inner Circle people, are the only English speakers in the world. But that Kachru's circles and the readings about Englishes changed my view a lot you know to actually learn the fact that there are also many Englishes spoken in Outer and Expanding Circle countries and they are more than Inner Circle people. I was very surprised and that I can also relate it to my own life interacting with customers where I work from different countries who don't speak Australian English (Tomoko)

The spread of English like for instance with the three circles you showed us today, I think that added up to about 3 and a half billion being exposed to English in one form or another, that's more than half the population of the world. I just found that really really interesting this idea that English could be that prevalent, and the different dialects, massive form of dialects. Definitely it would be useful for me to work in the department of foreign affairs and trade in the future because I will be interacting with people who speak English (Ogilvy)

As we further explore through the course, I learn about different varieties of English, lots and lots Englishes, that's very interesting because now I can look at my own life 
and I can see that Ive encountered different varieties of English in everyday life and what it means to me is that whole thing of how to interact using English and it's probably not even just 'English', but Englishes (Phil)

However, what needs to be highlighted is that the way the lecturers raised their awareness of world Englishes was believed by these students to have largely prompted them to critically re-examine their previous attitudes and to develop ones that would be important for communication in today's globalised world.

The recurring emphasis on reflections on/observations of their (or other speakers of English) experiences using English were reported by Cheolsoo and Tomoko to have encouraged them to re-examine their initial views of their own use of English. Not only had both Cheolsoo and Tomoko become aware of the influence of their own cultures and multilingual repertoires on their use of English, but they had become more confident in explaining and justifying why they used English the way they did.

Before I learnt EIL, I was not one of the pros for the EIL concept the first time, I thought my English is not something that reflects my worldview...but the more I study, the more I realise that, growing up in Korea and Australia, I have confronted a lot of cultural issues and that would be reflected in my English...So, for example in greetings stuff, I would actually prefer to use 'Have you had a dinner?' rather than 'How are you going?' That's important because in Korea we have been through Korean war and Korean ancestors were poor and they rarely had nice meal, so Koreans usually do greetings [in this way]. So, it's about caring about someone, one already had dinner or what they did...You know, different from Australians' use of 'How are you going?' or 'G'day mate', which I don't feel the 'connection' (Cheolsoo)

Actually knowing about this helped me feel a lot better and helped me accept myself better. I have learnt to appreciate the language like the accent I have and the culture I bring in with myself. I had to come to understand why I speak the way I do. Because I have multilingual background with myself, when I speak English I will have a lot of my cultural expressions brought in to English conversation. For example, even though I sometimes use ambiguous expressions in putting forward my arguments in writing essay, it doesn't mean I don't think critically. (Tomoko)

This practice of "sharing and talking about [students'] own experiences of using language" was reported to have also allowed participants to learn to understand and appreciate differences (Ogilvy), to gain knowledge about people from other cultures (Tomoko \& Phil), to learn to become open-minded and understanding (Tomoko \& Phil), and to critically revisit one's initial deficit views of others (Phil):

With the reflective observations, now I have come to understand about the different varieties of English and that these varieties don't pop up for no reasons, and there are significant cultural factors that influence the language, it's an organic process! Even if I, a native-speaker of Australian English, don't understand other varieties of English like Singaporean English, it doesn't mean that they are "incorrect" (Ogilvy) 
We have a lot of group activities we can share our opinion with other people, that was really helpful, if I didn't have that, I wouldn't know that there are other arguments, there are other people thinking the other way. I realise that many people in our class are from very very different cultural and language background and their experiences are really different from what I had or what you might have thought or so that sharing experiences open up our views and change my views about these people, about their Englishes as well. I could now accept other races, other accents, and became more patient, I could listen to people, I tried to understand because even the expressions is different, they still have some meanings from their own cultural backgrounds or they mean something (Tomoko)

you guys [lecturers] do that a lot which allows me to hear good ideas from my classmates, as in like the way they feel. A lot of what I find in EIL class is the students want to talk and they did open up their hearts. When I'm in the class, I hear all these great ideas and they're revealing themselves... When the 'back row' people talked, they brought up issues that I have never thought about it that way, like there was one case where they're talking about Hong Kong and how teaching is evolving in Hong Kong and they talked about the English teaching industry, how it's growing, and how people work in it... and I found out that one of the girls taught English to other Hong Kong students and helped her students go through learning process. So, she was great. And instead of like me thinking about them like they're a bunch of fobs, I started to think that holy crap...these people have education. This person is probably way smarter than me and I start to think that I am no longer on top of the world, Im probably below everybody else. (Phil)

In addition to his understanding and appreciation of differences, Ogilvy added that he had also become aware of the fact that even though he was a so-called native speaker of Australian English, that did not necessarily mean that his use of English was universally comprehensible and interpretable. Something as simple as "G'day or how you're going, the weather is bloody awful outside", he argued, would not translate across to "anyone from any country regardless of their proficiency in English if that person has not studied [his] dialect of English and is not familiar with such a culturally-loaded expression".

Moreover, Phil further claimed that not only had these stories, experiences, and thoughts shared by his classmates from other countries had driven him to "question [his] mentality of putting people into certain 'frameworks', but also to become more open and willing to learn further because "there's a lot of information out there in the world which you'll lose out if you stay close-minded".

I still have a lot to learn, I am still a learner, and English keeps changing and expanding and there are still so many people I have not met, so I cannot say that my English is complete...if there is ever such thing as complete! So, Im still learning and will keep learning (Phil)

Similarly, with his awareness of world Englishes, Ogilvy reported that he had been prompted to view how being a so-called 'native-speaker' of English does not mean that 
"[he] speaks correct and intelligible English, knows everything about English, and can converse with anyone in English". Rather, one still has to learn, especially in today's globalisation era, which, he anticipated, will influence the development of his idiolect:

As there are so many different varieties of English out there especially as Globalisation continues, Ill be forced to be a learner just because we are all exposed to so many different varieties of English, my vocab will continually be expanding as Im exposed to Indonesian English or Singaporean English or Indian English. I will keep learning as I go and will keep enriching my idiolect (Ogilvy)

In addition to the sharing of experiences and observations of linguistic and cultural differences, the interviews also revealed the effects of discussing issues about the politicisation of difference and the way these were brought to the students' attention on their attitudes towards differences. In teaching those topics, one activity that the participants believed had a long-lasting impact on them was the classroom activity called "linguistic-identity-switching activity" in which they were required to speak in only one particular unfamiliar variety of English selected by the lecturer and were penalised for any slight deviation. It was claimed that this activity and subsequent discussions of their struggle to participate in it prompted the participants to feel the importance of maintaining and taking pride in one's linguistic uniqueness (Tomoko \& Cheolsoo); to view the importance of developing effective intercultural communicative strategies (Cheolsoo) and learning from each other (Phil) as opposed to who should be emulated; and to become aware of the imperialistic nature and undesirable consequences of enforcing a particular group's standard language upon all (Ogilvy):

This activity had made me realised that people should not be afraid of using their own characteristics from their culture or their variety in their communication and really being 'original'. Being very original...not hiding your own identity and your own cultural essence into your language, and not afraid to put that into your English and your communication (Tomoko)

some Americans or Australians would want us to be like Australians or to become Australian or American speakers of English, but after those lectures and that activity in particular and of course knowing different accent and different varieties...Im so impressed...If we speak like Australians, it's like being colonised by Australian culture and English rather than keeping our identity cos we have other cultural and racial and other backgrounds. I have started to think that the most important thing is how you can express their thoughts and try to understand others' thoughts in today's international communicative settings (Cheolsoo's emphasis).

I have become less enthusiastic about that idea now. It's virtually impossible to expect people to speak in one accent, Creating a global region-free accent and a global Standard English is very unfair and very unduly difficult task to put upon them. Every country has their own important cultural traits and unique linguistic elements that they bring into their version of English. So, it's difficult to distil those things. One of the ways to express your culture is via language. And thinking about the offences 
that teaching only variety of Standard English cause in eradicating those cultures... like how you did to us in that activity [laughter]...that activity and the discussion made me think seriously about those issues. Like the indigenous Aborigines, I now really understand how they feel about the teaching and learning of Standard Australian English... I'm sure if you told the dreamtime story in Standard Australian English, it wouldn't sound anywhere nearest good as it's told in like the actual tongue or their version of Standard English it's designed to be told in, I think this goes for everybody, really! (Ogilvy)

I think after these activities, I realise that how communication is really important, it's not who should speaking which standard, I find that it is a key thing especially in breaking down barriers keep accommodating, to have that open...to open yourself up so that you can learn from them, see them as individual, not forcing people to speak like Americans or Canadians. I know I used to give up when people have weird accent, and believe they should change, but, now I think I should start to get acclimatised to different...diversity of English and it's more like normally I used to listen to the sound, but Im now listening to what they want to tell me, so, communication (Phil).

All in all, it can be seen that the curricula seem to have effectively prompted students to develop knowledge, mindsets, and skills for communicating effectively in English in today's multicultural social and professional environments.

\section{EIL program is very useful because it's more than just teaching us language} awareness, and being open, and also teaching us to change our perceptions, not just about English and yourself, but also perceptions on life, and the way you will work and how you will handle work, university work and working outside (Phil)

Although the teaching outcomes have mostly been positive, it does necessarily mean that the participants have completely been 'EIL-converted' or that people do not encounter any challenges in adopting these new views. However, what the data shows is that through learning about EIL, the participants seem to have, in Ogilvy's words, "definitely learnt a useful lesson already".

\section{Discussion and food-for-thought}

Thanks to globalisation, the inextricably interconnected world has prompted many universities to internationalise their education by developing efficacious programs that guide students to "live between cultures" (Besemeres \& Wierzbicka 2007, p.xiv). Though many universities, especially in Australia, claim that they have done so, many scholars (Briguglio 2007; Marginson 1999; Liddicoat 2003; Stella \& Liston 2008; Trevaskes et al. 2003) argue that the internationalisation of education is still far from a reality. Even if it has been implemented, it will often be monocultural-chauvinistic, parochial, imperialistic, and profit-driven. Challenging their claims, this paper has shown that there is an attempt by an international-oriented program offered in a university in Australia to truly execute the strong form of internationalisation by teaching international/intercultural communication from an international perspective mandated by 
that university's policy. Specifically, this case study on the EIL program demonstrates that the lecturers have designed their curricula based on their awareness of the unprecedented growth of transworld contacts, and therefore, seem to have been able to inspire their students to learn how to engage successfully with those contacts.

Firstly, since the forces of globalisation have increased the frequency of contacts and exchanges between people from diverse lingua-cultural backgrounds (McKay \& Bokhorst-Heng 2008; Scholte 2002), learning about and appreciating cultural differences is one of the core teaching elements of the program. The teaching of cultural differences goes beyond giving a superficial list of the behavioural traits of people from different countries. The students are continuously encouraged to use their knowledge of their own cultures to share with and, thus, educate their classmates (and lecturers) about their cultural values, worldviews, ideologies, and norms. They engage in educational dialogues in which they negotiate and interact with each other to make sense of practices, thoughts, and mindsets that are culturally unfamiliar to them. This dialoguing about each other's cultural differences in fact reflects rejections of the view of seeing international students on campus or in classrooms as an effective way to develop international/intercultural understanding (Stella \& Liston 2008). The teaching has shown that in order to achieve intercultural understanding, students need to study and engage in dialogue about each other's values, beliefs, worldviews, and cultural practices. As evidenced in the interviews, this practice of sharing and dialoguing has prompted them to critically question their ethnocentric views towards people from other cultures (Tomoko, Phil, Ogilvy), and to emphasise the importance of being open-minded because "there is a lot of information out there in the world" (Phil).

Secondly, the internationalisation of education that aims to equip students with the ability to communicate effectively in transworld encounters also goes beyond simply teaching English and/or using English as the medium of instruction as suggested by Carrol-Boegh (2005) and Manakul (2007). Informed by the EIL paradigm (McKay 2002; Sharifian 2009), the teaching of the pluricentricity of English is another core pedagogical focus of the EIL program. In addition to learning about each other's cultural uniqueness, students also explore, study, and dialogue about why (and in what way) do they, as monolingual or bi/multilingual speakers of English, communicate in English differently from each other; and how their use of English is a reflection of their sociocultural realities and cultural identities (and for some students, their multicultural and multilingual identities). The use of students' reflections on their own or observations of others' experiences of using/learning/teaching English as well as other languages is continuously encouraged in all assessment tasks and in classroom discussions. In light of this, the curricula of the EIL program have shown that the teaching of English that is based on the EIL paradigm is not necessarily, as Marginson (1999) has claimed, an imperialistic means to impose the 'Western' way of thinking and doing. Students have become aware of the fact that English, as an international language, is no longer the language of the 'West' but it has "organically processed" (Ogilvy) to reflect all its users' ways of thinking and doing (Canagarajah 1999; Jenkins 2009; Kachru 1986; McKay 2002; Smith 1976). Moreover, other languages have been incorporated, used, and discussed in the curricula. The hegemonic spread and its negative effects of English in the world, and the importance of preserving the multilinguality of a nation/society are issues that are also extensively discussed. Thus, the curricula of the program show that 
students have neither been taught to 'Westernise' nor 'Easternise' themselves, but to learn about and learn to negotiate each other's linguistic and cultural uniqueness, to be critically mindful of imperialistic acts and practices, and to confidently project their complex linguistic and cultural identities. The latter can be seen in the confidence Cheolsoo and Tomoko came to confidence in explaining and justifying their 'multilingually-flavoured' use of English. Therefore, unlike what Liddicoat claims (2003), a program that takes into account the pluralistic nature of English in teaching English as a language for international/intercultural communication can still reflect the rhetoric of plurality and interculturality and to accomplish internationalisation.

Lastly, although the teaching of cultural and linguistic difference lies at the heart of the internationalisation of education, it would not be internationalised enough if it did not address issues related to the politicisation of cultural and linguistic differences (Rizvi \& Walsh, 1998). Students may come to a class with an awareness of differences from encounters in their daily life. However, these differences are likely to be perceived and constructed from a deficit point of view, which they believe need to be 'remedied' unless this view is challenged. Such attitudes can be found in the participants' pre-EIL -learning attitudes towards speakers of Englishes from OCC and ECC and their use of English (such as fobs who can't speak English, foibles, speed-bumps, people who don't speak native-English... please don't speak), and their full support for "doing the Romans do [and] speaking standard native English". Therefore, the EIL program's activities and assessment tasks are not only designed to prompt students to appreciate linguistic and cultural differences, but also to critically examine and develop/propose strategies to deal with any practices and ideologies (including their own) that implicitly marginalise one group and unjustly empower the other. These activities and tasks seem to have successfully prompted the participants to question their initial deficit/ethnocentric/native-speakerist views of the different varieties of English and its speakers, and to value learning about linguistic and cultural diversity as a never-ending journey ("I am still learning"). These are the essential attributes with which students should leave an internationalised program.

In the light of all this, this paper has showcased how one program has approached internationalisation to prepare its graduates for operating effectively today's international and intercultural globalised environments. Based on the curricula described and students' responses, the EIL program seems to have successfully accomplished its university's mission of internationalisation of education. This is, however, not to claim that this particular EIL program should be the only successful model of an academic program that teaches intercultural communication based on the EIL paradigm. It may, however, serve as one example for educators who are interested in developing or teaching a similar EIL program. Therefore, this paper would like to offer some modest suggestions for developing a program that teaches intercultural communication based on the EIL paradigm:

- Multiculturalism and Multilingualism should lie at the heart of the program

Students need to learn about, appreciate, and negotiate cultural differences. Voices of students from diverse lingua-cultural backgrounds need to be made audible in order to promote intercultural dialogues and learning. Awareness of multilingualism as the 
reality of today's communicative exchanges and therefore the importance of knowledge of/competence in other languages needs to be raised.

- The pluralisation of English and the implications for communication need to be extensively discussed

Students need to be made aware of the existence of world Englishes, and to learn to understand their roles in contributing to the pluralisation of English. One way to begin is to allow students to reflect on, observe, explore, and dialogue with others about the way they use English as a natural mirror of their cultural worldviews, norms, and cultural/linguistic identities).

- Issues of the politicisation of cultural and linguistic differences need to be introduced and discussed in the curriculum with 'extra care'

Students also need to be made aware of the political constructions of difference (difference as deficiency or diversity) and its undesirable impacts on identity constructions these have. In order to do this, opportunities need to be given to students to observe existing ideologies and practices that implicitly promote and perpetuate social and linguistic inequality and/or to reflect on their past experiences of encountering such ideologies and practices in a variety of contexts. In response to this, students will need to investigate ways in which they can learn to respectfully and professionally deal with such ideologies and practices in their future encounters.

Competing interests

The author declares that he has no competing interests.

Received: 16 March 2013 Accepted: 14 May 2013

Published: 24 June 2013

References

Alsagoff, L, SL McKay, G Hu, and WA Renandya. 2012. Principles and Practices for Teaching English as an International Language. New York: Routledge.

Besemeres, M, and A Wierzbicka. 2007. Translating Lives: Living with Two Languages and Cultures. Queensland: University of Queensland Press.

Bloch, B, and D Starks. 1999. The many faces of English: Intra-language variation and its implications for international business. Corporate Communications: An International Journal 4(2): 80-88.

Bourdieu, P. 1991. Language and symbolic power. Cambridge: Polity Press.

Briguglio, C. 2007. Educating the business graduate of the 21st century: communication for a globalised world. International Journal of Teaching and Learning in Higher Education 19: 8-20.

Canagarajah, S. 1999. Resisting Linguistic Imperialism in English Teaching. Oxford: Oxford University Press.

Carrol-Boegh, A. 2005. Internationalisation and Teaching through English. Educate journal 5(2): 19-30.

Clyne, M, and F Sharifian. 2008. English as an international language: Challenges and Possibilities. Australian Review of Applied Linguistics 31(3): 1-16.

Crystal, D. 1997. English as a Global Language. Cambridge: Cambridge University Press.

Crystal, D. 1999. "From out in the left field? That's not cricket": Finding a focus for the language curriculum. In The Workings of Language: From Prescriptions to Perspectives, ed. RS Wheeler. Westport: Praeger.

Graddol, D. 1999. The decline of the native speaker. AlLA Review 13: 57-68.

Graddol, D. 2001. English in the future. In Analysing English in a Global Context, ed. A Burns and C Coffin. New York: Routledge.

Graddol, D. 2006. English Next. London: British Council.

Haigh, MJ. 2002. Internationalisation of the curriculum: designing inclusive education for a small world. J Geogr High Educ 26(1): 49-66.

Hayward, F. 2000. Preliminary status report 2000: Internationalization of US higher education. Washington: American Council of Education.

Holliday, A. 2005. The struggle to teach English as an International Language. Oxford: Oxford University Press.

Jameson, F. 1998. Notes on Globalisation and Philosophical Issues. In The Cultures of Globalisation, ed. F Jameson and M Miyoshi. Durham, NC: Duke University.

Jenkins, J. 2009. World Englishes: A resource book for students, $2^{\text {nd }}$ edition. London/New York: Routledge. 
Kachru, B. 1986. The Alchemy of English. Oxford: Pergamon Press.

Kachru, Y, and LE Smith. 2008. Cultures, Contexts, and World Englishes. London: Routledge.

Knight, J. 2003. Internationalization of higher education practices and priorities: 2003 IAU survey report. Paris: International Association of Universities.

Knight, J, and W De. 1997. Internationalisation of higher education: a conceptual framework. In Internationalisation of Higher Education in Asia Pacific Countries, ed. J Knight and W De. Amsterdam: The EAIE.

Kumaravadivelu, B. 2008. Cultural Globalisation and Language Education. New Haven: Yale University Press.

Liddicoat, AJ. 2003. Internationalisation as a concept in higher education: Perspectives from policy. In Australian perspectives on internationalising education, ed. S Trevaskes, S Eisenchlas, and AJ Liddicoat. Melbourne: Language Australia.

Lippi-Green, R. 1997. English with an accent: Language, ideology, and discrimination in the United States. London: Routledge.

Manakul, W. 2007. Role of English in Internationalization of Higher Education: The Case of the Graduate School of Engineering, Hokkaido University. Journal of Higher Education and Lifelong Learning 15: 155-162.

Marginson, S. 1999. After globalisation; emerging politics of education. Journal of Education Policy 14(1): 19-31.

Marlina, R. 2010. Teachers of Englishes, English Teaching Professional 66. Chichester: Keyways Publishing.

Marlina, R, and HJ Ahn. 2011. 'Internationalised' English teaching materials? Please think again: A Korean case study, Conference Paper for Korean Association of Teachers of English (KATE) Conference, "Empowering English Teachers in the Globalization Era". Seoul, South-Korea: Yonsei University.

Marlina, R, and R Giri. 2009. ELICOS English and Curriculum: Perspectives on their internationalisation, Conference Paper presented at 2009 English Australia Conference, "Engaging with the many dimensions of ELICOS: teaching, learning, supporting, marketing, leading". Melbourne, Victoria.

Matsuda, A. 2002. "International understanding" through teaching world Englishes. World Englishes 21(3): 436-440.

Matsuda, A. 2005. Preparing future users of English as an International language. In Teaching English from a global perspective: Case studies in TESOL series, ed. A Burns. TESOL: Alexandria.

Matsuda, A. 2012a. Principles and Practices of Teaching English as an International Language. Bristol: Multilingual Matters.

Matsuda, A. 2012b. Teaching Materials in EIL. In Principles and Practices for Teaching English as an International Language, ed. L Alsagoff, SL McKay, G Hu, and WA Renandya. New York: Routledge.

McKay, S. 2002. Teaching English as an International Language. Oxford: Oxford University Press.

McKay, SL. 2003. ElL Curriculum Development. RELC J 34(1): 31-47.

McKay, SL. 2012. Teaching materials for English as an International Language. In Teaching English as an International Language: Principles and Practices, ed. A Matsuda. Bristol: Multilingual Matters.

McKay, S, and WD Bokhorst-Heng. 2008. International English in its sociolinguistic contexts: Towards a socially sensitive ElL pedagogy. London: Routledge.

Phillipson, R. 1992. Linguistic Imperialism. Oxford: Oxford University Press.

Rizvi, F, and L Walsh. 1998. Difference, globalisation and the internationalisation of curriculum. Aust Univ Rev 2:7-11.

Rubdy, R. 2001. Creative Destruction: Singapore's Speak Good English movement. World Englishes 20(3): 341-355.

Scholte, JA. 2002. What is globalisation? The definitional issue - Again, Centre for the Study of Globalisation and Regionalisation (CSGR) Working Paper 109/02, 1-34. Coventry: University of Warwick.

Sharifian, F. 2009. English as an International Language: Perspectives and Pedagogical Issues. Bristol: Multilingual Matters.

Sharifian, F. 2011. Cultural Conceptualisations and Language. Amsterdam: John Benjamins \& Co.

Skutnabb-Kangas, T, and R Phillipson. 1989. Mother Tongue: The Theoretical and Sociopolitical Construction of a Concept. In Status and Function of Languages and Language Varieties, ed. U Ammon. Berlin, New York: Walter de Gruyter \& Co

Smith, L. 1976. English as an International Auxiliary Language. RELC J 7(2): 38-42.

Stella, A, and C Liston. 2008. Internationalisation of Australian Universities: Learning from Cycle 1 Audits. Melbourne: Australian Universities Quality Agency.

Stier, J. 2004. Taking a critical stance towards internationalization ideologies in higher education: idealism, instrumentalism and educationalism. Glob Soc Educ 2(1): 83-98.

Trevaskes, S, S Eisenchlas, and AJ Liddicoat. 2003. Australian Perspectives on Internationalising Education. Melbourne: Language Australia.

Universities Australia. 2009. The nature of international education in Australian universities and its benefits. http://www. universitiesaustralia.edu.au/page/submissions_-reports/commissioned-studies/benefits-of-international-education/, accessed on 19th May 2012.

Yang, R. 2002. University Internationalisation: its meaning, rationales and implications. Int Educ 13(1): 81-95.

doi:10.1186/2191-5059-3-5

Cite this article as: Marlina: Globalisation, internationalisation, and language education: an academic program for global citizens. Multilingual Education 2013 3:5. 